\title{
Heat Treatment and Thirty-Day Storage Period Do Not Affect the Stability of Omega-3 Fatty Acid in Brown Flaxseed (Linum Usitatissimum) Whole Flour
}

\author{
Dayane de C. Morais ${ }^{1}$, Érica A. Moraes ${ }^{1}$, Maria Inês de S. Dantas ${ }^{1}$, Júlia C. C. Carraro ${ }^{1}$, Cassiano 0. \\ da Silva ${ }^{1}$, Paulo R. Cecon², Hércia S. Duarte Martino, Sônia M. Rocha Ribeiro ${ }^{{ }^{*}}$
}

${ }^{1}$ Department of Nutrition and Health, Federal University of Viçosa, Viçosa, Brazil; ${ }^{2}$ Department of Computer Science, Federal University of
Viçosa, Viçosa, Brazil.
Email: sribeiro@ufv.br

Received February $1^{\text {st }}$, 2011; revised March $3^{\text {rd }}$, 2011; accepted March $8^{\text {th }}, 2011$.

\begin{abstract}
This study was conducted to verify if the processing and storage of brown flaxseed whole flour result in loss of functional properties, such as reduced linolenic acid content, increased lipid peroxidation and sensory changes. The flours were obtained from seeds dried by heat treatment in oven at $150^{\circ} \mathrm{C}$, for 15 minutes and subsequent grinding to obtain flour with a particle size of 20 mesh. Meal samples, with and without synthetic antioxidants (BHA and BHT combined, at $100 \mathrm{ppm}$ each), were stored for a thirty-day period, under similar conditions to those used commercially. The linolenic acid content was quantified by gas chromatography. Lipid peroxidation was analyzed by thiobarbituric acid reactive substance assay. Color and flavor were evaluated by sensory tests. The linolenic acid content and lipid peroxidation did not significantly change after processing or during storage. Fluctuations in color and flavor occurred during storage, but at the end of 30 days, only the heat treatment presented negative effect $(p<0.05)$ on the parameter color. Heat treatment and thirty-day storage period do not change the stability of n-3 fatty acid in brown flaxseed whole flour.
\end{abstract}

Keywords: Flaxseed, Flour, Omega-3, Lipid Peroxidation, Heat Treatment

\section{Introduction}

The increasing interest of consumers in disease prevention and the scientific evidence about the benefits of functional foods have stimulated the food industry to invest in the development of healthier products. The increased intake of alpha linolenic acid (omega-3) has been associated with prevention of chronic noncommunicable diseases [1-4] and nutritional benefits[5]. Thus, it is suggested that the highest intake of omega-3 is important to correct the high ratio of omega-6/omega- 3 in Western diets [6], which have been associated with the installation of inflammatory processes related to the pathogenesis of several diseases [7].

Flaxseed (Linum usitatissimum L.) has approximately $40 \%$ of total lipids, out of which about 50 to $55 \%$ is composed of $\alpha$-linolenic acid (omega-3), and 15 to $18 \%$, of $\alpha$-linoleic acid (omega-6), with a favorable balance of polyunsaturated, monounsaturated and saturated fatty acids [8,9]. Flax seed is considered the highest vegetable source of essential fatty acid for human diet [10,11], due to its high concentration of $\alpha$-linolenic acid. It also provides other bioactive compounds, such as phenolic compounds, including lignans, vitamin $\mathrm{E}$ and dietary fiber [11].

Flaxseed has generally been used as raw whole seeds in food. However, the seeds are not completely digested in the digestive tract, and the bioavailability of its bioactive compounds, including linolenic acid, can be impaired.

It is assumed that the milling of flaxseed is an excellent strategy to increase the bioavailability of the bioactive compounds [12]. The seed heat treatment may increase product life by reducing humidity and improving the physical properties of food, making it more suitable to partially replace starch and eliminating cyanogenic compounds, which have toxic potential [13]. Therefore, the mechanical and heat processing of flaxseed is the 
most appropriate way to solve the problem already mentioned.

However, due to the high content of polyunsaturated fatty acids, seeds may be susceptible to oxidation by exposure to heat and oxygen. The oxidation of lipids in flaxseed is undesirable, since it decreases the functional potential of seeds as a source of omega-3, and produces toxic compounds to human health [14]. There are few studies that investigated the stability of linolenic acid in flaxseed meal during processing and storage. The food industry is interested in knowing the processing conditions that preserve the linolenic acid from flaxseed, since flour is an attractive technological strategy for the use of flaxseed to enrich products and as a source of bioactive compounds.

The present study aimed to evaluate the oxidative stability of linolenic acid from brown flaxseed whole flour after processing and during a 30-day storage period.

\section{Materials and Methods}

\subsection{Experimental Design}

The study on flaxseed oxidative stability during processing was composed of nine treatments subdivided in a $3 \times$ 3 factorial scheme (three types of ovens and three sub-treatments with binomial combinations of time, temperature and power). For the study on oxidative stability during storage, the experiment was arranged in a 3 $\times 5$ factorial scheme ( 3 types of meal and 5 storage periods) to evaluate the lipid peroxidation level and linolenic acid content. These experiments were arranged in a completely randomized design with three replications in duplicates.

\subsection{Heat Treatment of Whole Flaxseed Flours (Time $\times$ Temperature $\times$ Equipment)}

The flours were prepared from seeds dried by the heat treatments described in Table 1. After drying, the seeds were cooled to room temperature and ground in a blender (Britânia Bellagio - V5) at average speed, for three minutes. Then, they passed through a 20-mesh sieve. The control treatment consisted of raw flaxseeds ground under the same conditions. The moisture content of flours and seeds was determined according to the AOAC [15] to quantify the humidity reduction.

\subsection{Storage Conditions}

The sample achieved from heat treatment in air circulation oven $\left(150^{\circ} \mathrm{C}\right.$ for 15 minutes) was selected from the flours analyzed for oxidative stability during storage. Samples under three different storage conditions were prepared for the lipid peroxidation assay, and linolenic acid quantification: I) meal obtained from heat treated seeds without antioxidants - TT; II) meal obtained from heat treated seeds containing combined synthetic antioxidants (butylhydroxyanisole -BHA at $25 \mathrm{ppm}$ and butylhydroxytoluene- BHT at $25 \mathrm{ppm}$ added after thermal treatment and cooling) - ATT and III) meal obtained from raw seed, as the control - RS. The flours were divided into $100 \mathrm{~g}$ samples, packed in polypropylene bags and sealed manually. The flours were stored, without light control, at room temperature $\left(20-25^{\circ} \mathrm{C}\right)$, for thirty days. The samples were removed at $0,7,14,21$ and 30 days of storage for sensory analysis. Sample aliquots were stored in an ultra-freezer $\left(-80^{\circ} \mathrm{C}\right)$ for the lipid peroxidation assay and linolenic acid quantification.

\subsection{Lipid Peroxidation Analysis and Linolenic Acid Content in the Flours}

The thiobarbituric acid reactive substance (TBARS) test was used to assess lipid peroxidation according to Buege and Aust [16]. Briefly, flour samples $(0.5 \mathrm{~g})$ were transferred to test tubes containing TBARS reagent $(2.0 \mathrm{~mL})$ composed of trichoroacetic acid $15 \%(\mathrm{w} / \mathrm{w})$ and thiobar-

Table 1. Types of heat treatments for seed drying.

\begin{tabular}{|c|c|c|c|c|c|}
\hline \multicolumn{2}{|c|}{ Domestic Oven } & \multicolumn{2}{|c|}{ Oven with air circulation } & \multicolumn{2}{|c|}{ Microwave Oven } \\
\hline Time (min) & Temperature $\left({ }^{\circ} \mathrm{C}\right)$ & Time (min) & Temperature $\left({ }^{\circ} \mathrm{C}\right)$ & Time (min) & Power (W) \\
\hline 15 & 120 & - & - & - & - \\
\hline 15 & 150 & - & - & - & - \\
\hline 15 & 180 & - & - & - & \\
\hline- & - & 15 & 60 & - & - \\
\hline- & - & 15 & 120 & - & - \\
\hline- & - & 15 & 150 & - & - \\
\hline- & - & - & - & 2 & Moderate \\
\hline- & - & - & - & 5 & Moderate \\
\hline- & - & - & - & 8 & Moderate \\
\hline
\end{tabular}


in Brown Flaxseed (Linum Usitatissimum) Whole Flour

bituric acid $0.375 \%(\mathrm{w} / \mathrm{v})$ in hydrochloride acid solution $(0.25 \mathrm{~mol} / \mathrm{L})$. The reaction mixture was maintained in water bath at $100^{\circ}$ for 15 minutes. Then, the mixture was cooled and centrifuged at $980 \mathrm{~g}$ for 5 minutes. The absorbance was read at $535 \mathrm{~nm}$ with a Shimadzu UV-1601 spectrophotometer. The malondialdehyde (MDA) concentration was calculated using a molar absorption coefficient of $1.56 \times 10^{5} \mathrm{M}^{-1} \cdot \mathrm{cm}^{-1}$. The fat content of the samples was assessed and the results were expressed as MDA equivalent per gram of lipid.

The linolenic acid was quantified by gas chromatography. Lipid extraction from samples of whole flaxseed flour $(0.1 \mathrm{~g})$ was performed according to Folch, Lees and Stanley [17]. The extracted lipids were submitted to saponification and esterification to obtain methyl ester derivatives [18]. Sample aliquots $(1.0 \mu \mathrm{L})$ containing methyl esters were injected into a gas chromatograph, (SHIMADZU AOC-17) equipped with an auto-injector and an integrator (Shimadzu C-R7A). Capillary column Carbowax $(30 \mathrm{~mm} \times 0.25 \mathrm{~mm})$ was maintained at $200^{\circ} \mathrm{C}$ for 10 minutes; and at heating from $6^{\circ} \mathrm{C}$ to $240^{\circ} \mathrm{C}$ for 16.6 minutes. The following chromatographic conditions were adopted: injector and detector temperatures of $240^{\circ} \mathrm{C}$ and $260^{\circ} \mathrm{C}$, respectively, split ratio set at 1:20. Nitrogen was used as a carrier gas at a $0.5 \mathrm{~mL} / \mathrm{min}$ flow rate, and $100 \mathrm{Kpa}$ pressure. A linolenic acid analytical curve ranging from 0 to $1000 \mathrm{ppm}\left(r^{2}=0.996\right)$ was used to quantify omega-3 fatty acid.

\subsection{Sensory Tests}

Twenty trained judges, 17 females and 3 males between 19 and 25 years of age, carried out the sensory tests. Color and aroma parameters were evaluated using the multiple comparison test proposed by the Brazilian Association of Technical Standards [19]. Samples (standard and tests) were arranged in a completely randomized block design. The judges received a standard sample identified by the letter $\mathrm{P}$ and test samples assigned with random three-digit code numbers. Judges were asked to evaluate each test sample in comparison to the standard sample (heat treated meal and meal prepared immediately before testing). For the standard sample, the comparison scale ranged from much extremely below the standard (score 1) to extremely better than standard (score 7), and a score of 4 was considered equal to the standard. All protocols complied with the ethical committee guidelines and the experiment was approved by the CERH/ UFV- Committee on Ethics in Research involving $\mathrm{Hu}-$ mans of the Federal University of Viçosa, Brazil.

\subsection{Statistical Analysis}

The data were statistically analyzed using ANOVA and regression analysis. For the qualitative factors (heat treatments and types of meal), the averages were compared by the Tukey test at $5 \%$ probability. The quantitative factor (days of storage) and the models were selected based on the significance of the regression coefficients and the biological phenomenon.

\section{Results and Discussion}

Regardless of the equipment and binomial combinations (time, temperature and power), the heat treatment did not affect the lipid peroxidation of the flours $(p>0.05)$. The MDA concentration in the heat treated seed meal ranged from 0.0052 to $0.4050 \mathrm{nmol}$ of $\mathrm{MDA}$ equivalents per gram of lipid, and from 0.0060 to $0.2650 \mathrm{nmol}$ of MDA equivalents per gram of lipid in the raw seed meal. These results demonstrated that brown flaxseed wholemeal is stable in heat treatment under the conditions used. The oxidative degradation of flaxseed oil was previously demonstrated in conditions of extreme degradation, by microwave heating [20].

Considering the oxidative stability of flaxseed meal for the drying methods, we select the heat treatment in air circulation oven $\left(150^{\circ} \mathrm{C}\right.$ for 15 minutes $)$ for the analysis of stability during storage. No difference was observed in lipid peroxidation levels among the flours during the 30day storage $(p>0.05)$ (Table 2). Under the conditions of this study, the combination of reduced moisture content (from $4.67 \%$ in seeds to $2.33 \%$ in flaxseed flour) and the addition of antioxidant additives (BHT and BHA) did not improve flour preservation.

The linolenic acid content did not differ among the flours during the evaluated storage time (Table 3 ). There was no statistically significant difference in the content of the other fatty acids: myristic, palmitic, oleic, linoleic (data not shown).

The results corroborated the oxidative stability of omega-3 fatty acid, which was demonstrated by the peroxidation marker (malondialdehyde). Likewise, Malcoulmson et al. reported that meals from two flaxseed varieties stored for 128 days at room temperature and protected from light presented no changes in their linolenic acid content [21]. In our research, the samples were also maintained at room temperature, but not protected from light, similarly to commercial conditions. These results support the hypothesis of the existence of components in the flaxseed matrix that protect polyunsaturated fatty acids against oxidation [22,23].

Table 4 shows the scores assigned to the flour parameters color and aroma in the sensory test during the 30-day storage. After 7 days of storage, the TT flour presented significant difference from the other samples for the parameter color, which was regularly considered in- 
Table 2. Malondialdehyde concentration (nmol/gram of lipid) in brown flaxseed wholemeal subjected to different heat treatments (TT, ATT, RS) and storage periods.

\begin{tabular}{cccc}
\hline Storage (days) & TT $^{\mathrm{a}}$ & $\mathbf{A T T}^{b}$ & RS $^{c}$ \\
\hline 0 & $0.2217^{\mathrm{a}}$ & $0.2334^{\mathrm{a}}$ & $0.1781^{\mathrm{a}}$ \\
7 & $0.3400^{\mathrm{a}}$ & $0.2810^{\mathrm{a}}$ & $0.2662^{\mathrm{a}}$ \\
14 & $0.2750^{\mathrm{a}}$ & $0.2156^{\mathrm{a}}$ & $0.3251^{\mathrm{a}}$ \\
21 & $0.1383^{\mathrm{a}}$ & $0.1447^{\mathrm{a}}$ & $0.1858^{\mathrm{a}}$ \\
30 & $0.2304^{\mathrm{a}}$ & $0.2261^{\mathrm{a}}$ & $0.2593^{\mathrm{a}}$ \\
\hline
\end{tabular}

TT $^{a}$ : heat treatment without synthetic antioxidants, $\mathbf{A T T}^{b}$ : heat treatment with combined synthetic antioxidants (butylhydroxyanisole at 25 ppm and butylhydroxytoluene at $25 \mathrm{ppm}), \mathbf{R S}^{c}$ : raw seed. Means followed by the same letter in the lines are not significantly different (Tukey test at 5\% probability).

Table 3. Linolenic acid content (grams/100 g) in brown flaxseed wholemeal subjected to different heat treatments (TT, ATT, RS) and storage periods.

\begin{tabular}{cccc}
\hline Storage (days) & TT $^{a}$ & ATT $^{b}$ & RS $^{c}$ \\
\hline 0 & $10.440^{\mathrm{a}}$ & $13.528^{\mathrm{a}}$ & $9.866^{\mathrm{a}}$ \\
7 & $13.566^{\mathrm{a}}$ & $7.053^{\mathrm{a}}$ & $14.012^{\mathrm{a}}$ \\
14 & $9.038^{\mathrm{a}}$ & $13.951^{\mathrm{a}}$ & $8.517^{\mathrm{a}}$ \\
21 & $13.247^{\mathrm{a}}$ & $12.403^{\mathrm{a}}$ & $14.166^{\mathrm{a}}$ \\
30 & $12.605^{\mathrm{a}}$ & $14.437^{\mathrm{a}}$ & $9.496^{\mathrm{a}}$ \\
\hline
\end{tabular}

$\mathbf{T T}^{a}$ : heat treatment without synthetic antioxidants, $\mathbf{A T T}^{b}$ : heat treatment with combined sinthetic antioxidants (butylhydroxyanisole at 25 ppm and butylhydroxytoluene at $25 \mathrm{ppm}$ ), $\mathbf{R S}^{c}$ : raw seed. Means followed by the same letter in the lines are not significantly different (Tukey test at $5 \%$ probability).

Table 4. Scores for color and aroma of brown flaxseed wholemeal subjected to different heat treatments (TT, ATT, RS) and storage time.

\begin{tabular}{|c|c|c|c|c|c|c|}
\hline \multirow{2}{*}{ Storage (days) } & \multicolumn{3}{|c|}{ Color } & \multicolumn{3}{|c|}{ Aroma } \\
\hline & $\mathbf{T T}^{a}$ & $\mathbf{A T T}^{b}$ & $\mathbf{R S}^{c}$ & $\mathbf{T T}^{a}$ & $\mathbf{A T T}^{b}$ & $\mathbf{R S}^{c}$ \\
\hline 0 & $4.10^{\mathrm{a}}$ & $2.65^{\mathrm{b}}$ & $4.60^{\mathrm{a}}$ & $4.00^{\mathrm{a}}$ & $2.55^{\mathrm{b}}$ & $3.35^{\mathrm{a}}$ \\
\hline 7 & $2.70^{\mathrm{b}}$ & $4.25^{\mathrm{a}}$ & $4.05^{\mathrm{a}}$ & $2.75^{\mathrm{b}}$ & $3.55^{\mathrm{a}}$ & $3.05^{\mathrm{a}}$ \\
\hline 14 & $2.60^{\mathrm{b}}$ & $4.35^{\mathrm{a}}$ & $4.15^{\mathrm{a}}$ & $2.65^{\mathrm{b}}$ & $3.85^{\mathrm{a}}$ & $3.55^{\mathrm{a}}$ \\
\hline 21 & $2.10^{\mathrm{b}}$ & $4.15^{\mathrm{a}}$ & $4.25^{\mathrm{a}}$ & $2.30^{\mathrm{b}}$ & $3.40^{\mathrm{a}}$ & $3.05^{\mathrm{a}}$ \\
\hline 30 & $2.00^{\mathrm{b}}$ & $3.90^{\mathrm{a}}$ & $4.15^{\mathrm{a}}$ & $2.30^{\mathrm{b}}$ & $3.05^{\mathrm{a}}$ & $2.85^{\mathrm{a}}$ \\
\hline
\end{tabular}

$\mathbf{T T}^{a}$ : heat treatment without synthetic antioxidants, $\mathbf{A T T}^{b}$ : heat treatment with combined synthetic antioxidants (butylhydroxyanisole at 25 ppm and butylhydroxytoluene at $25 \mathrm{ppm}), \mathbf{R S}^{c}$ : raw seed. Means followed by the same letter in the lines are not significantly different (Tukey test at $5 \%$ probability).

ferior to the standard. This result demonstrated that the combination of BHA and BHT contributed to the preservation of the color attribute, which was negatively affected by the heat treatment. Oscillations were also observed in scores for aroma during storage, but there was no significant difference among the samples after thirty days of storage, and scores remained between equal and slightly below the standard, demonstrating that the addition of antioxidants did not affect the analyzed attribute.

Figure 1 shows the profile of the parameters aroma and color of samples stored with and without antioxidants. The flour-TT obtained decreasing scores for color and flavor throughout the storage period (Figure 1(a)). Flour-ATT achieved increasing scores for color and aroma up to the $14^{\text {th }}$ storage day and decreasing scores from the twentieth day onwards. But the mean scores at the final storage period were higher than the scores attributed at time zero (Figure 1(b)). No effect of time of storage on aroma and color was found for raw meal (RS).

The results indicated that the heat treatment negatively affected the preservation of color and aroma of the brown flaxseed wholemeal. The addition of BHA and BHT contributed to the preservation of both parameters only from the $7^{\text {th }}$ to the $21^{\text {st }}$ day. The flour obtained from raw seeds showed color and aroma stability higher than the other two.

In summary, no significant differences were observed 


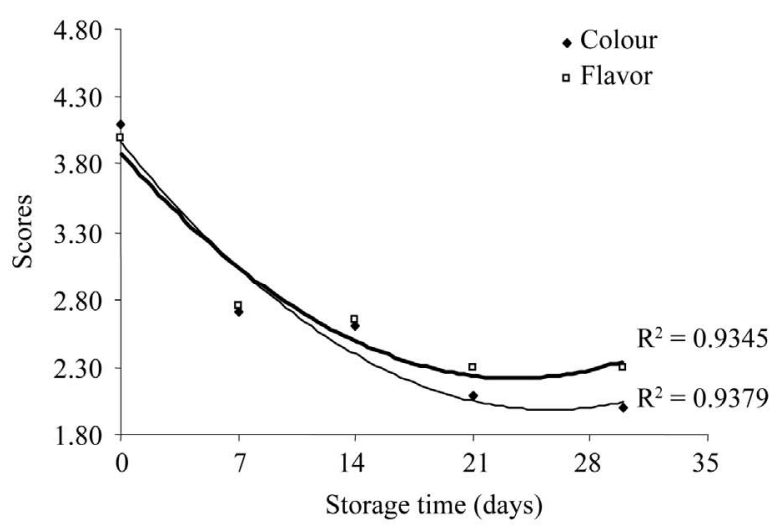

(a)

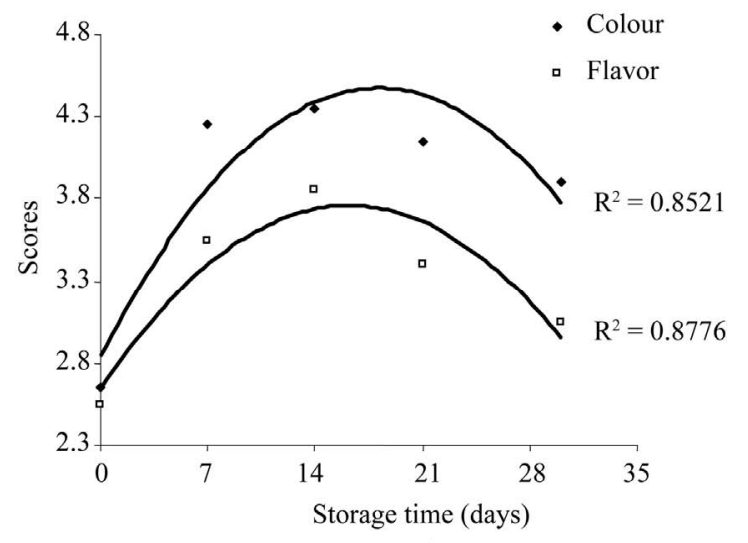

(b)

Figure 1. Scores for aroma and color of brown flaxseed wholemeal without (a) and with synthetic antioxidants (b) at different storage times. Color: $Y=-0.005 x^{2}+0.1802 x+2.8421$ and Aroma: $Y=-0.0042 x^{2}+0.1371+2.6469$.

peroxidation level after processing and during the storage period, indicating oxidative stability of the lipid fraction of flaxseed. However, some changes were sensory perceptible in the flours analyzed. This demonstrates the importance of sensory tests which are able to detect subtle changes in a food matrix, in magnitudes which are than the statistical significance. Further studies should be carried out in order to identify compound degradations that interfere in the sensory attributes of flaxseed meal during storage. The appearance of a product causes a great impact on consumer's choice. Color is the most relevant characteristic and is considered the first criterion for the acceptance or rejection of products. However, the changes in color and flavor can be minimized when the flaxseed wholemeal is used as an ingredient in novel products.

\section{Acknowledgements}

The authors acknowledge the Brazilian agencies for their support to the research (FAPEMIG, CNPq and CAPES) and $\mathrm{Mr}$. Schaeffer for kindly supplying the flaxseeds.

\section{REFERENCES}

[1] G. Barceló-Coblijn, E. J. Murphy, et al., "Flaxseed Oil and Fish-Oil Capsule Consumption Alters Human Red Blood Cell n-3 Fatty Acid Composition: A Multiple-Dosing Trial Comparing 2 Sources of n-3 Fatty Acid," American Journal of Clinical Nutrition, Vol. 88, No. 3, 2008, pp. 801-809.

[2] C. M. Bassett, D. Rodriguez-Leyva and G. N. Pierce, "Experimental and Clinical Research Findings on the Cardiovascular Benefits of Consuming Flaxseed," Applied Phy- siology, Nutrition, and Metabolism, Vol. 34, No. 5, 2009, pp. 965-974. doi:10.1139/H09-087

[3] L. T. Bloedon and P. P. O. Szapary, "Flaxseed and Cardiovascular Risk," Nutrition Review, Vol. 62, No. 1, 2004, pp. 18-27. doi:10.1111/j.1753-4887.2004.tb00002.x

[4] A. Patade, L. Devareddy, E. A. Lucas, K. Korlagunta, B. P. P. Daggy and B. H. Arjmandi, "Flaxseed Reduces Total and LDL Cholesterol Concentrations in Native American Postmenopausal Women," Journal of Women's Health, Vol. 17, No. 3, 2008, pp. 355-366. doi:10.1089/jwh.2007.0359

[5] T. M. Oliveira, M. R. Pirozi and J. T. S. Borges, "Elaboração de pão de sal Utilizando Farinha Mista de Trigo e Linhaça," Alimentos e Nutrição, Vol. 18, No. 2, 2007, pp. $141-150$

[6] A. Simopoulos, "The Importance of the Omega-6/Omega-3 Fatty Acid Ratio in Cardiovascular Disease and Other Chronic Disease," Experimental Biology and Medicine, Vol. 233, No. 6, 2008, pp. 674-688. doi:10.3181/0711-MR-311

[7] P. P. C. Calder, R. Albers, J. M. Antoine, S. Blum, R. BourdetSicard, G. A. Ferns, et al., "Inflammatory Disease Processes and Interactions with Nutrition," British Journal of Nutrition, Vol. 101, Supplement 1, 2009, pp. 1-45. doi:10.1017/S0007114509377867

[8] J. F. Carter, "Potential of Flaxseed and Flaseed Oil in Baked Goods and Other Products in Human Nutrition," Cereal Foods World, Vol. 38, No. 10, 1993, pp. 753-759.

[9] B. Bozan and F. Temmelli, "Chemical Compositon and Oxidative Stability of Flax, Safflower and Poppy Seed and Seed Oils," Bioresource Technoloy, Vol. 99, No. 14, 2008, pp. 6354-6359. doi:10.1016/j.biortech.2007.12.009

[10] K. Prasad, "Flaxseed: A Source of Hypocholesterolemic and Antiatherogenic Agents," Drug News Perspective, Vol. 13, No. 2, 2000, pp. 99-104. doi:10.1358/dnp.2000.13.2.662239

[11] B. D. Oomah, "Flaxseed as a Functional Food Source," Journal of Sciences Food Agriculture, Vol. 81, No. 9, 2001, pp. 889-894.

[12] J. A. Austria, M. N. Richard, M. N. Chaline, A. C. Edel, L. J. Malcolmson, C. M. Dupasquier and G. N. Pierce, "Bioavailability of Alpha-Linolenic Acid in Subjects after 
Ingest of Three Differents Forms of Flaxseed," Journal of the American College of Nutrition, Vol. 27, No. 2, 2008, pp. 214-221.

[13] M. R. Haque and J. H. Bradbury, "Total Cyanide Determination of Plants and Foods Using the Picrate and Acid Hydrolysis Methods," Food Chemistry, Vol. 77, No. 1, 2002, pp. 107-114. doi:10.1016/S0308-8146(01)00313-2

[14] M. Burenjargal and N. Totani, "Cytotoxic Compounds Generated in Heated Oil and Assimilation of Oil in Wistar Rats," Journal of Oleo Science, Vol. 58, No. 1, 2009, pp. 1-7. doi: $10.5650 /$ jos. 58.1

[15] AOAC International, "Official Methods of Analysis of AOAC International," Association of Analytical Communities, Gaithersburg, 1997.

[16] J. A. Buege and S. D. Aust, "Microsomal Lipid Peroxidation," In: S. Fleisher and L. Packer, Eds., Methods in Enzymology, Academic Press, San Diego, Vol. 52, 1978, pp. 302-310.

[17] L. Folch, M. Lees and G. N. Stanley, "A Simple Method for the Isolation and Purification of Total Lipids from Animal Tissues," Journal of Biological Chemistry, Vol. 226, No. 1, 1957, pp. 497-509.

[18] L. Hartmann and B. C. A. Lago, "Rapid Preparation of
Fatty Acid Methyl Esters from Lipids," Laboratory Practices, Vol. 22, No. 6, 1973, pp. 475-477.

[19] Associação Brasileira de Normas Técnicas, "Teste de Comparação Múltipla em Análise Sensorial dos Alimentos e Bebidas," NBR 13526, ABNT, Rio de Janeiro, 1995. p. 9.

[20] M. D. Guillén and A. Ruis, "Study by Means of $1 \mathrm{H} \mathrm{Nu}$ clear Magnetic Resonance of the Oxidation Process Undergone by Edible Oils of Different Natures Submitted to Microwave Action," Food Chemistry, Vol. 96, No. 4, 2006, pp. 665-674. doi:10.1016/j.foodchem.2005.04.013

[21] L. J. Malcoulmson, R. Przybylski and J. K. Daun, "Storage Stability of Milled Flaxseed," Journal of the American Oil Chemists' Society, Vol. 77, No. 3, 2000, pp. 235-338.

[22] R. Abuzaytoun and F. Shahidi, "Oxidative Stability of Algal Oils as Affected by Their Minor Components," Journal of Agriculture and Food Chemistry, Vol. 54, No. 21, 2006, pp. 8253-8260. doi:10.1021/jf061047s

[23] R. Amarowicz, U. Wanasundara, J. Wanasundara and F. Shahidi, "Antioxidant Activity of Ethanolic Extracts of Flaxseed in a $\beta$-Carotene Linoleate Model System," Journal of Food Lipids, Vol. 1, No. 2, 1993, pp. 111-117. doi:10.1111/j.1745-4522.1993.tb00239.x 